\title{
Potential for domestic thermal storage to absorb excess renewable energy in a low carbon future
}

\author{
Avinash Vijay \\ Department of Engineering Science \\ University of Oxford \\ Oxford, UK \\ avinash.vijay@eng.ox.ac.uk
}

\author{
Sivapriya Mothilal Bhagavathy \\ Department of Engineering Science \\ University of Oxford \\ Oxford, UK \\ sivapriya.mothilalbhagavathy@eng.ox. \\ ac.uk
}

\author{
Malcolm McCulloch \\ Department of Engineering Science \\ University of Oxford \\ Oxford, UK \\ malcolm.mcculloch@eng.ox.ac.uk
}

\begin{abstract}
Transition to low carbon electricity generation is key to meet the global emission targets. This requires a drastic shift from the current energy mix dominated by coal and gas to renewables especially wind and solar. Due to the intermittent nature of renewable generation, the probability of generationdemand mismatch is high. This mandates the need for storage of the excess generation in order to prevent curtailment. Utilisation of domestic hot water tanks to absorb this excess provides us with an economical option at a nominal incremental cost. This paper develops a method to quantify the capacity of hot water tanks required and the potential savings in a low carbon future. The results are explained with the UK as a case study. The results indicate that between one and ten Terra Watt hours of curtailment can be expected in the UK in the year 2040. Eighty percent of this energy can be captured if one-fifth of all houses in the UK are equipped with smart hot water tanks.
\end{abstract}

Keywords - Domestic hot water, Energy storage, Renewable energy, Decarbonisation, Optimisation

\section{INTRODUCTION}

This paper explores the utilisation of domestic hot water tanks, an asset available in one in two dwellings in the UK [1], [2], to absorb the excess generation. This work makes three contributions. Firstly, we quantify the amount of energy that will be curtailed in the UK in the year 2040 while satisfying emission targets set by the government. Secondly, we analyse the extent to which smart hot water tanks can be used to absorb the energy that would otherwise be curtailed. Finally, we also quantify the value that can be delivered to the consumer if such smart hot water tanks were to be deployed. It is worth noting that the generation plants are connected at the transmission level and the hot water storage is connected at the distribution level. The cumulative or collective effects of the resources present in the distribution system will have a similar impact on the resources in the transmission system.

This problem is important since a special report by the Intergovernmental Panel on Climate Change highlights that ambitious mitigation action is needed to limit global warming to $1.5^{\circ} \mathrm{C}$ [3]. There is a general consensus in UK and Europe that immediate action is required to deal with the unavoidable consequences of climate change [4]. Such a transition will require an energy mix dominated by renewables especially wind and solar as shown in the Future Energy Scenarios published by National Grid in the UK [9]. Their intermittent nature will result in a mismatch between the demand and the generation. Domestic energy storage in different forms, thermal or electrical will be key to provide support to the electricity network during the events of mismatch [5]-[7]. In comparison with battery storage, hot water tanks have longer lifespans, lower degradation and nominal incremental cost.
The attractiveness of this form of storage also stems from the fact that around 30\% of the energy demand is for domestic water heating and space heating/cooling [8] as shown in Fig. 1 and around $20 \%$ of this demand is for domestic water heating as shown in Fig. 3.

From the analysis, it can be observed that with around onefifth of households with hot water tanks used for storage of excess energy, it is possible to eliminate more than $80 \%$ of the curtailment in all the scenarios. The paper further explores the potential savings achievable to the end users assuming the excess energy is supplied to them at nominal or zero cost. The analysis also shows potential savings of around $£ 50$ per year per household under high penetration of decentralised resources.

The paper begins with the details of the model, the different scenarios and the sources of data used for the evaluation in section II. This is followed by the results which inform the conclusion in section III and conclusions and future work in section IV.

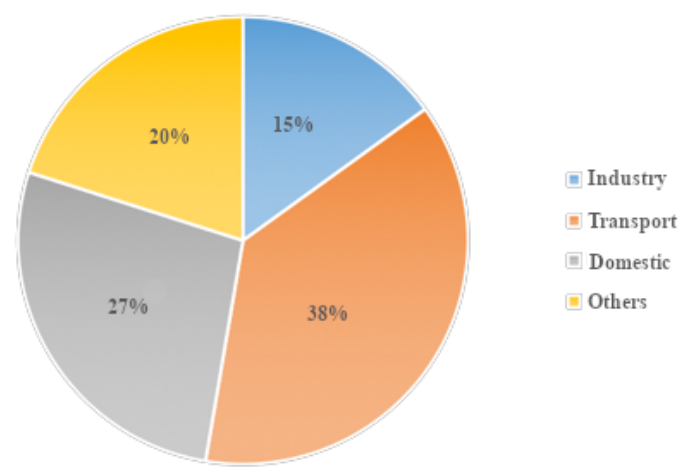

Fig. 1. Total energy consumption in the UK per sector [10]

\section{METHODS}

\section{A. Mathematical Model}

The dispatch model is based on the least cost optimisation of generation and storage assets. The objective function is a combination of fuel and carbon costs as shown in equation (1).

$$
\text { Minimize } \sum_{i \in I} \sum_{j \in J_{i}} \sum_{t \in T}\left(c_{j, t}^{\text {fuel }}+c_{j, t}^{\text {carbon }}\right)
$$

where $\mathrm{I}, \mathrm{J}_{\mathrm{i}}$ andT are the set of all nodes, conventional generators connected to node $\mathrm{i}$ and time periods respectively. The symbol c represents cost. The problem is subject to a set of constraints shown below. The supply-demand balance is governed by equation (2). Here p represents power from 
conventional sources, $\mathrm{q}$ represents the power associated with storage assets, $\mathrm{L}$ represents the net load, $\mathrm{p}^{\text {int }}$ represents interconnector flow, $\mathrm{p}^{\mathrm{c}}$ represents curtailment, $\mathrm{S}_{\mathrm{i}}$ represents the set of all electrical storage assets in node $\mathrm{i}$ and $\mathrm{I}_{\mathrm{i}}$ is the set of all other nodes connected to node i. Equation (3) represents the feasible operating envelope of the conventional generators. Equation (4) represents the feasible operating envelope of the storage assets.

$$
\begin{aligned}
& \sum_{j \in J_{i}}\left(p_{j, t}\right)+\sum_{s \in S_{i}}\left(q_{s, t}\right)=L_{t, i}+\sum_{k \in I_{i}}\left(p_{k, t}^{i n t}\right)+p_{t, i}^{c} \\
& \forall t \in T, \forall i \in I \\
& p_{j, t} \in \Pi_{j, t}, \forall t \in T, \forall j \in J_{i}, \forall i \in I \\
& q_{s, t} \in \Gamma_{t}, \forall t \in T, s \in S_{i}, \forall i \in I
\end{aligned}
$$

It is worth noting that this work classifies solar and wind as intermittent sources that can be curtailed if necessary and nuclear power plants as inflexible generation with no ramping capacity. The model simulates two electricity grids one for the UK and one for Europe with one interconnector for the flow of power between the two regions.

The energy that can be stored in hot water tanks is considered as equal to the energy of the hot water consumed in the household as it is not possible to dump more energy than what can be consumed by the household. Energy is calculated using equation (5) for each month of the year.

$$
E=m C_{p} \Delta T
$$

where $m$ is the mass of the hot water consumed, $C_{p}$ is the specific heat capacity of water $\left(4186 \mathrm{~J} / \mathrm{kg} /{ }^{\circ} \mathrm{C}\right)$ and $\Delta T$ is the temperature difference between the hot water temperature and the ambient temperature.

For a household with $n$ people residing in the household, the hot water demand per day for each month is calculated using equation (6) from [11].

$$
V=(36+25 n) \times s
$$

where $s$ is the seasonality factor for that month.

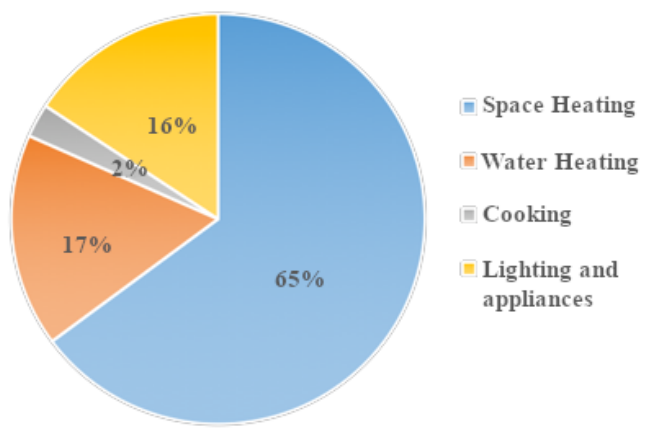

Fig. 2 - End use consumption within domestic sector [10], [11]

\section{B. Scenarios}

This work considers a low carbon future that is likely to exist in the year 2040. Curtailment in the UK will be dependent on several factors such as demand, renewable output, the energy mix in the UK and Europe. Of these factors, the energy mix is of prime importance since it represents the planning and investment decisions taken during this time. There is one scenario for the UK and three for Europe as seen in Table I. Europe is represented by the aggregation of many countries and hence, the diversity of future possibilities that need to be modelled is greater. All the scenarios were created by the respective Transmission System Operators in UK and Europe. They were chosen because extensive modelling, stakeholder engagement and regulatory analysis has gone into their development.

The Two Degrees (TD) scenario chosen for the UK is meant to explore how the UK can achieve the 2050 emissions target through aggressive investment in larger and centralised low carbon technologies. It assumes high penetration of centralised renewable sources, energy efficiency measures and smart technologies. A similar strategy is employed in the Global Climate Action (GCA) scenario for Europe. Emphasis is on large scale renewables and nuclear. The Distributed Generation (DG) scenario for Europe focuses on prosumers. A more decentralised approach pays particular attention to end-user technologies. Electric vehicles, PV and batteries see widespread adoption by end-users. The Sustainable Transition (ST) scenario for Europe seeks a quick and economicalCO2 reduction by replacing coal and lignite by gas. This can be viewed as a business as usual scenario which heavily depends on the emergence of innovative technologies in the 2040s to achieve emissions targets.

All three scenarios assume $19.8 \mathrm{GW}$ of interconnector capacity between the UK and Europe. As this exceeds the capacity associated with any single conventional generation type, it underscores the importance of conditions in Europe. Due to the lack of comprehensive information on grid-scale storage capacity in the scenario documentation, minimum values required to enable feasible operation were chosen.

TABLE I. ENERGY MIX ENERGY MIX FOR THE YEAR 2040 [9], [12] (TD - Two DEgREes, GCA - GLOBAL ClimATE ACTION, DG DISTRIBUTED GENERATION, ST - SUSTAINABLE TRANSITION)

\begin{tabular}{|l|c|c|c|c|}
\hline \multicolumn{1}{|c|}{ Region } & UK & \multicolumn{3}{c|}{ Europe } \\
\hline \multicolumn{1}{|c|}{ Scenario } & TD & GCA & DG & ST \\
\hline Nuclear (GW) & 18.6 & 79.2 & 72.4 & 72.4 \\
\hline Solids fired (GW) & - & 34.5 & 75.8 & 51.0 \\
\hline Gas fired (GW) & 13.2 & 164.3 & 206.2 & 168.6 \\
\hline Oil fired (GW) & - & 16.6 & 9.2 & 60.0 \\
\hline Hydro (GW) & 2.1 & 61.5 & 61.5 & 61.5 \\
\hline Pumped Store (GW) & 2.7 & 69.4 & 57.7 & 57.8 \\
\hline Pumped Store (GWh) & 27.6 & 555.1 & 461.2 & 462.6 \\
\hline Grid Scale Storage (GW) & 27.4 & 144.6 & 85.2 & 101.6 \\
\hline Grid Scale Storage (GWh) & 54.8 & 2458.7 & 170.5 & 609.8 \\
\hline Wind (GW) & 62.8 & 537.9 & 437.6 & 413.3 \\
\hline Solar (GW) & 41.1 & 639.6 & 803.8 & 347.5 \\
\hline
\end{tabular}

\section{Data Sources}

Time series data for the UK was accessed from publicly available sources[13]. Fuel prices were taken from the updated energy and emissions projections released by the UK government[14]. Future energy mix values for the UK was based on the values released by National Grid in their Future Energy Scenarios document[9]. The carbon price was also taken from the same source[9]. Time series data for Europe was taken from [15]. Future energy mix values for Europe were taken from the Ten Year Network Development Plan released by the European Network of Transmission System Operators for Electricity[12]. 
The mass $m$ used in equation (5) is dependent on the number of households $N_{h w}$, the composition of households and the seasonal factor for the month. The total number of households, $N$, is calculated by dividing the maximum curtailment that occurs in each of the scenarios by the typical hot water tank heating element which is taken as $3-\mathrm{kW}$ given in [16]. The seasonal factor and temperature difference for each month are as given in Table II [8]. The percentage composition of households is considered to be similar to the national average as given in Table III [17].

TABle II. SEASONAl Factors [7]

\begin{tabular}{|c|c|c|}
\hline Month & Seasonal Factor & $\begin{array}{c}\text { Temperature } \\
\text { difference }\end{array}$ \\
\hline January & 1.1 & 41.2 \\
\hline February & 1.06 & 41.4 \\
\hline March & 1.02 & 40.1 \\
\hline April & 0.98 & 37.6 \\
\hline May & 0.94 & 36.4 \\
\hline June & 0.9 & 33.9 \\
\hline July & 0.9 & 30.4 \\
\hline August & 0.94 & 33.4 \\
\hline September & 0.98 & 33.5 \\
\hline October & 1.02 & 36.3 \\
\hline November & 1.06 & 39.4 \\
\hline December & 1.1 & 39.9 \\
\hline
\end{tabular}

Table III. Percentage Composition of Households In the UK [17]

\begin{tabular}{|l|c|}
\hline $\begin{array}{l}\text { Number } \\
\text { of people }\end{array}$ & \% of households \\
\hline 1 & 29 \\
\hline 2 & 35 \\
\hline 3 & 16 \\
\hline 4 or more & 20 \\
\hline
\end{tabular}

III. RESULtS

\section{A. Coincidence}

Define Before analysing the results of the power dispatch model, it is worth considering the conditions which lead to curtailment. Due to the large interconnector capacity, curtailment will not happen if either side of the interconnector has demand that needs to be satisfied by conventional sources. Curtailment will only happen when both the UK and Europe have excess inflexible low carbon generation. In this work, we refer to this as coincidence. Coincidence is a good indicator of when to expect curtailment when we run the simulation. Variation in total monthly coincidence is shown in Fig. 3.

It is immediately clear that the Distributed Generation scenario is far more likely than the others to encounter large scale curtailment followed by Global Climate Action and Sustainable Transition. This is due to the high levels of coincidence seen between April and August in the Distributed Generation and Global Climate Action scenarios.

\section{B. Curtailment}

The power dispatch problem discussed in Section II-A is run for the year 2040. The model calculates generation from each type of source and the charge/discharge strategy for all storage assets throughout the year. From these values, we can calculate the excess generation from inflexible sources that cannot be absorbed by storage. This excess generation will have to be curtailed. The results of the simulation are presented in Table IV.

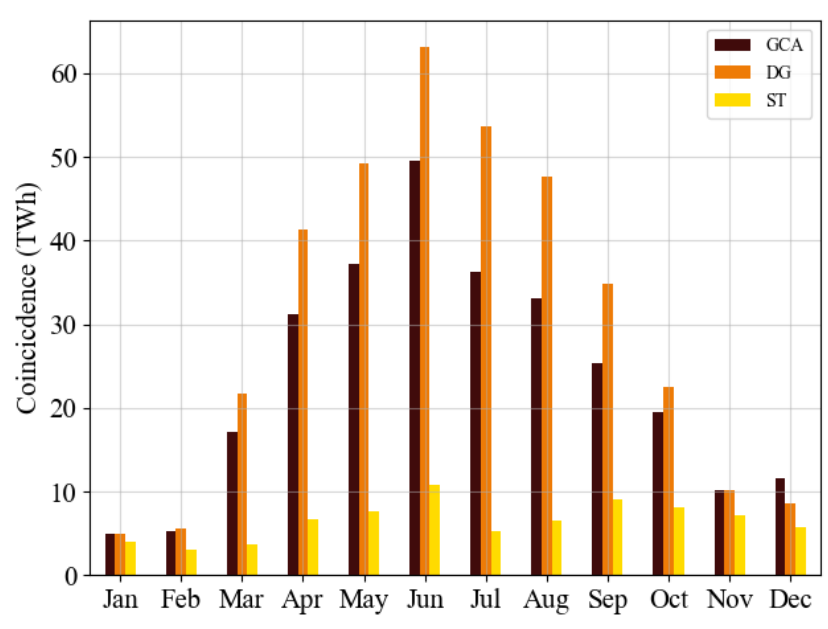

Fig. 3. Coincidence in each scenario

As expected, the trend from the coincidence discussion influences curtailment results. The Distributed Generation scenario records the highest total curtailment followed by Global Climate Action and Sustainable Transition.

TABLE IV. CURTAILMENT RESULTS

\begin{tabular}{|l|c|c|}
\hline & $\begin{array}{c}\text { Max. curtailment } \\
\text { (GW) }\end{array}$ & $\begin{array}{c}\text { Total Curtailment } \\
\text { (TWh) }\end{array}$ \\
\hline GCA & 45.2 & 6.3 \\
\hline DG & 42.6 & 10.8 \\
\hline ST & 27.5 & 1.0 \\
\hline
\end{tabular}

The lower penetration of solar and wind in the Sustainable Transition scenario leads to a lower value of instantaneous and total curtailment. The highest maximum curtailment value, however, was seen in the Global Climate Action scenario. This can be attributed to the higher penetration of large-scale low carbon sources in this scenario. Such sources, especially wind turbines, can lead to high instantaneous values of curtailment. The variation of monthly curtailment is shown in Fig. 4.

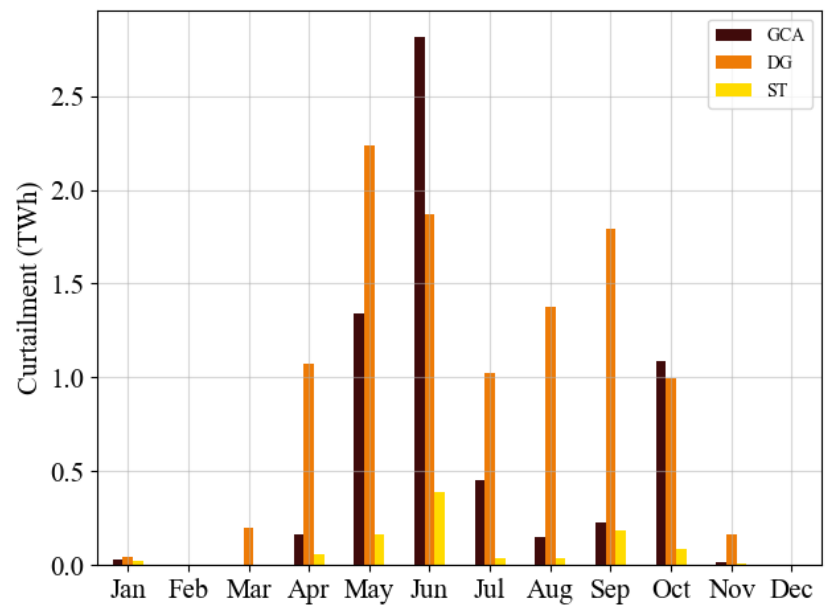

Fig. 4. Curtailment in each scenario

It can be inferred that the grid-scale storage absorbs a significant portion of the excess low carbon generation since the monthly curtailment values are much lesser than the monthly coincidence values shown in Table IV. Nevertheless, the levels of curtailment observed are not 
trivial. Curtailment levels are higher in summer than other seasons in all scenarios. It is worth noting that curtailment in Distributed Generation scenario is consistently above $1 \mathrm{TWh}$ per month for more than half the year. This is not seen in the other scenarios and is the reason why total curtailment was much higher in Table IV.

\section{Energy Storage Capacity}

The storage available is dependent on hot water consumption levels in households. This is calculated using the equations presented in Section II-A. The number of households or hot water tanks is determined using the maximum instantaneous curtailment. The results are presented in Fig. 5. Global Climate Action with the highest maximum curtailment (see Table IV) has the most houses and the highest storage capacity, followed by Distributed Generation and Sustainable Transition. It is understandable that there is a lower demand for hot water in the summer months. Thus, the storage available during these months is also low.

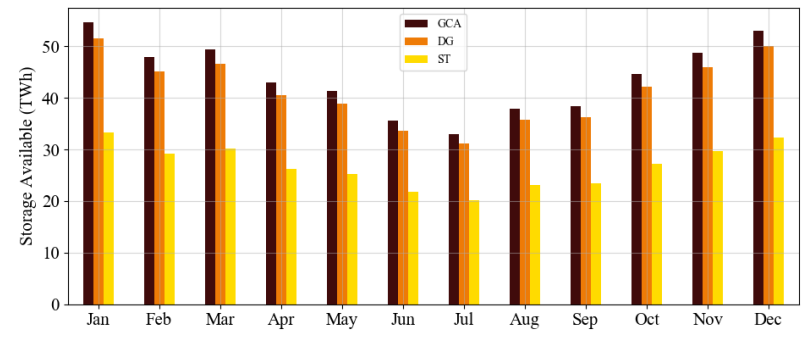

Fig. 5. Storage available throughout the year

\section{Penetration Trade-off}

In the previous section, the number of tanks deployed was calculated so as to absorb all of the curtailed energy available. This discussion can be improved further by analysing the amount of energy captured when the penetration of hot water tanks is varied. This has been presented in Fig. 6. The results indicate that there exists a trade-off between the number of hot water tanks and energy captured. There penetration level required to capture all curtailment varies according to the scenario. This is around thirty-five percent for Sustainable Transition, thirty-eight percent for Distributed Generation and fifty percent for Global Climate Action.

TABLE V. CONSUMER-END VALUE

\begin{tabular}{|l|c|}
\hline Scenario & $\begin{array}{c}\text { Consumer Value } \\
(\mathbf{f} / \text { house/year })\end{array}$ \\
\hline GCA & 29.3 \\
\hline DG & 53.2 \\
\hline ST & 7.6 \\
\hline
\end{tabular}

\section{E. Consumer-end Value}

The consumer receives all of the energy that would otherwise be lost via curtailment. This energy will displace the electricity they would otherwise consume to heat up their hot water tanks for the next day. We calculate the savings per consumer based on the electricity tariff projections provided in [18]. We use half of the retail price of electricity to charge the hot water tanks, as is the case with the Economy 7 tariffs that is prevalent among consumers with hot water tanks. The maximum value that can be delivered to the consumer in each scenario is presented in Table $\mathrm{V}$.

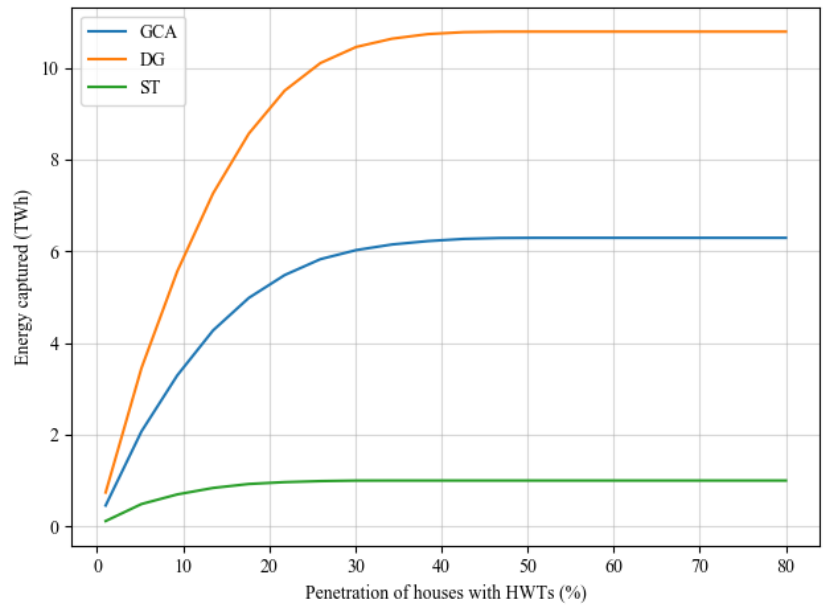

Fig. 6. Analysis of energy captured according to penetration level of hot water tanks

\section{CONCLUSIONS}

In this work, we assess the potential for domestic hot water storage to absorb excess generation in a low carbon future. The magnitude of curtailment is quantified through the use of a power dispatch model. Different scenarios are used to represent conditions in the UK and Europe. The results indicate that between curtailment between $1 \mathrm{TWh}$ and 10 TWh can be expected in the UK in the year 2040. Eighty percent of this energy can be captured if one-fifth of all houses in the UK are equipped with smart hot water tanks. Consumerend value is dependent on the energy mix adopted and varies between $£ 7$ and $£ 53$ per household.

This analysis can be improved further with spatial resolution of curtailment values and hot water tank capacities. This work will benefit from detailed studies of the transmission and distribution network. But such studies are warranted only if domestic hot water storage is found to provide value in the aggregated case studied here. Since our analysis points out that hot water storage can in fact provide significant value, we will focus on such aspects in future works. Thus, we will also be able to point out which regions will have a pressing need for hot water tank roll out in the near future. Finally, this work stems from a demonstrator project that aims to roll out these smart hot water tanks in the UK. There is a wealth of learnings to be discussed around the transition from publication to actual implementation. This will also be covered in a separate publication.

\section{ACKNOWLEDGMENT}

This research was funded by the 'Power. Energy. Technology. Efficiency.' project, awarded to the University of Oxford by Innovate UK, under project reference: 103307.

\section{REFERENCES}

[1] Department of Energy \& Climate Change, United Kingdom housing energy fact file. 2013.

[2] P. J. Boait, D. Dixon, D. Fan, and A. Stafford, "Production efficiency of hot water for domestic use," Energy Build., vol. 54, pp. 160-168, 2012.

[3] P. J. First, "Global warming of 1.5 C An IPCC Special Report on the impacts of global warming of $1.5 \mathrm{C}$ above pre-industrial levels and related global greenhouse gas emission pathways, in the context of strengthening the global response to the threat of climate change, ," 2018. 
[4] European Commission, The EU Strategy on adaptation to climate change. 2013.

[5] P. Balcombe, D. Rigby, and A. Azapagic, "Energy selfsufficiency, grid demand variability and consumer costs: Integrating solar PV, Stirling engine CHP and battery storage," Appl. Energy, vol. 155, pp. 393-408, 2015.

[6] S. Goutte and P. Vassilopoulos, "The value of flexibility in power markets," Energy Policy, vol. 125, pp. 347-357, 2019.

[7] E. Garnier and R. Madlener, "Day-ahead versus intraday valuation of demand-side flexibility for photovoltaic and wind power systems," 2014.

[8] European Commission, An EU Strategy on Heating and Cooling. 2016.

[9] National Grid, Future Energy Scenarios. 2018.

[10] Department of Business Energy and Industrial Strategy (BEIS), Digest of UK Energy Statistics (DUKES). 2018.

[11] Department of Energy \& Climate Change, Measurement of domestic hot water consumption in dwellings. 2011.

[12] European Network of Transmission System Operators for Electricity (ENTSOE), Ten year Network Development Plan. 2018.
[13] Elexon Limited, "Balancing Mechanism Resporting Service," 2019. [Online]. Available: https://www.bmreports.com/. [Accessed: 12-Aug-2019].

[14] Department of Business Energy and Industrial Strategy (BEIS), Updated energy and emissions projections. 2019.

[15] C. Gerbaulet, C. von Hirschhausen, C. Kemfert, C. Lorenz, and P. Oei, "Scenarios for decarbonizing the European electricity sector," in 2017 14th International Conference on the European Energy Market (EEM), 2017, pp. 1-6.

[16] F. Oldewurtel et al., "A framework for and assessment of demand response and energy storage in power systems," in 2013 IREP Symposium Bulk Power System Dynamics and Control-IX Optimization, Security and Control of the Emerging Power Grid, 2013, pp. 1-24.

[17] Office for National Statistics, Households and Household Composition in England and Wales: 2001-11. 2011.

[18] Committee on Climate Change, Energy Prices and Bills Report. 2017. 